arm loops is the same. The molecules are asymmetric because the side arm is inserted in the left-hand sequence of the stem in one and the right-hand sequence of the other. Alternatively, the side arm could be inserted at the same point but with sequences with opposite $5^{\prime} \rightarrow 3^{\prime}$ and $3^{\prime} \rightarrow 5^{\prime}$ polarities. In either case, the orientation of the bases in the terminal stem loop is different with regard to the orientation of those in the side arm loop. It is therefore possible to envisage a protein which might bind to these two loops of one molecule, but not those in the other. This could generate handedness or asymmetry at the molecular level.

I have suggested elsewhere ${ }^{3}$ that secondary and tertiary RNA structures, encoded by maternal DNA, may be important cytoplasmic determinants in the egg and

developing embryo. One of the bestknown examples of asymmetry is the direction of coiling of the shell of snails, and in Limnaea this is known to be inherited maternally ${ }^{46}$. With regard to genetic control, only one or other of asymmetric molecules like those in the figure might be transcribed from DNA, and mutations could lead to reversal or loss of asymmetry.

ROBIN HOLLIDAY

CSIRO Laboratory for Molecular Biology, PO Box 184, North Ryde,

New South Wales 2113,

Australia

1. Galloway, J. Nature 346, 223-224 (1990).

2. Brown, N.A. \& Wolpert, L. Development 109, 1-9 (1990). 3. Holliday, R. New Biologist 1, 337-343 (1989).

4. Boycott, A.E. \& Diver, C. Proc. R. Soc. B95, 207 (1923)

5. Sturtevant, A.H. Science 58, 269-270 (1923).

6. Boycott, A.E., Diver, C., Garstang, S.L. \& Turner, F.M. Phil. Trans. R. Soc. B219, 51-131 (1930).

\title{
Earthquake lights and seismicity
}

SIR - Sightings of earthquake lights and other similar anomalous phenomena in the night sky have been reported for many centuries. But it is only recently that such controversial phenomena have been linked to the geological features and tectonic processes underlying earthquake activity $^{1,2}$.

Earthquake light (EQL) sightings reported between 1 November 1988 and 21 January 1989 in the Saguenay region $200 \mathrm{~km}$ north of Quebec city, Canada (Fig. 1) were found to be associated with 54 seismic shocks ${ }^{3}$. The seismic activity was recorded by a network of portable seismometers distributed near the epicentre by the Geological Survey of Canada, 24 hours after the 23 November foreshock (magnitude 4.8). About 60 hours later, the main shock of magnitude 6.5 was felt as far south as Washington, DC.

We asked 52 sighting reporters, found through local radio stations ănd newspapers, to answer a five-page questionnaire. We found three types of luminescence: sparkings without accompanying sound; diffuse light, such as heat-lightning intensity at sunset or sunrise illuminating a good part of the sky; and vertical and

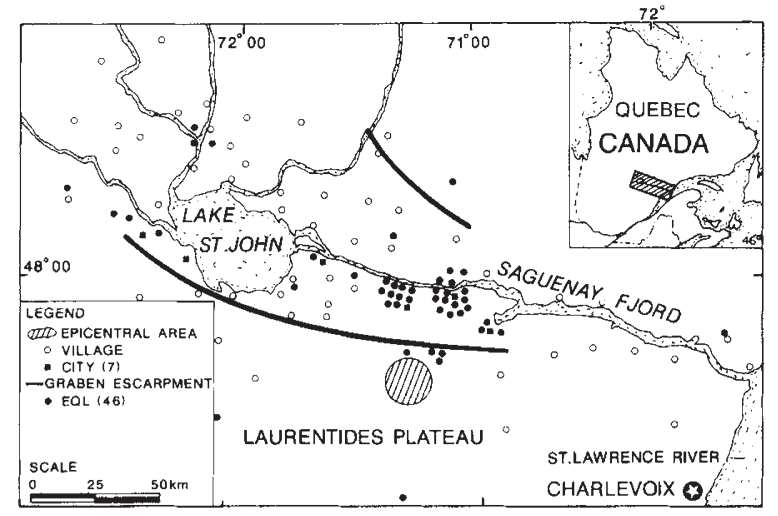

FIG. 1 The Saguenay-Lake Saint John region, showing the epicentral area of the November 1988 earthquakes as well as the EQL sightings and population spatial distributions. horizontal aurora-like stripes. The first category of EQLs was more closely related to the atmosphere than to the Earth's surface. Fireballs a few metres in diameter often popped out of the ground in a repetitive manner at distances of up to only a few metres away from the observers. Others were seen several hundred metres up in the sky, stationary or moving. Some observers described dripping luminescence droplets, rapidly disappearing a few metres under the stationary fireballs. Only two fire-tongues on the ground were reported, one on snow and the other on a paved parking space without any apparent surface fissure. The colours most often identified were orange, yellow, white and green. Some luminosities lasted up to 12 min. Out of the 46 EQLs reported, $70 \%$ were observed 4-35 km north of the epicentral area, reflecting the geographical distribution of the main cities in the region.

Regardless of the fact that before the 23 November earthquake, no seismic activity greater than 1.5 magnitude had been detected by the nearest permanent Charlevoix seismic-monitoring station of the Geological Survey of Canada Network (100 km to the southeast), erratic EQL sightings were reported as early as 1 November. Of the 46 EQLs reported from then until the end of January $1989,39(84 \%)$ were seen between 1 and 27 November (Fig. 2). During that month, 2 main shocks, followed by 31 aftershocks, with a cumulative magnitude sum of 66.5 , were recorded out of a total of $54(\Sigma M=$ 83.7) until the end of January 1989. The greatest daily number of EQL sightings is highly synchronous with the timing of the two main
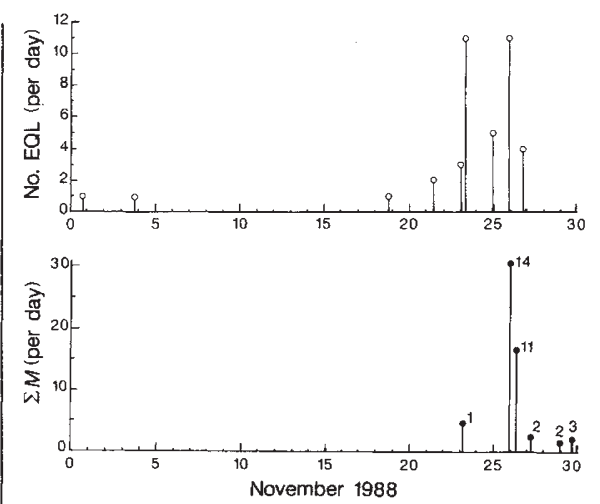

FIG. 2 November mean daily temporal distributions of the number of EQLs reported per day (O) (top) and the sum of the daily magnitudes of seismic events (bottom). No. of seismic events per day.

shocks. On 23 and 25 November, respectively, at 0412 and 1846 (EST), 11 sightings were reported. No seismic activity was recorded on the 24 November, but sightings were observed during the evening of the 21 until the evening of the 26 November. Excluding the foreshock, during which 8 of the 11 EQLs were witnessed simultaneously with the seismic event at $0420,93 \%$ of all luminescences in November were recorded between 1800 and 2400 . Because only a few people are awake after midnight, and events are in any case likely to be underreported, the total number of EQL events was probably substantially underestimated. On the other hand, all seismic events of magnitude greater than 0.1 are detected by the seismometer network. These discrepancies make statistical analysis of the two phenomena difficult. Nevertheless, five shocks $(M=0.8-3.6 ; \Sigma=10.1)$ were registered between 16 and 22 January 1989 and, unlike the three EQLs of December, they were well synchronized with the six EQLs of 16, 19 and 21 January.

Several suggestions have been made ${ }^{46}$ to explain these luminous seismotectonic electromagnetic emissions, but none is fully satisfactory. The roles of many physical and chemical factors associated with each seismic event still remain to be elucidated. Furthermore, the inherent difficulties associated with the gathering of controllable field information on such rare phenomena limit the progress of research.

Quebec University,

INRS-Eau, PO Box 7500 ,

Ste-Foy, Quebec,

Canada G1V 4 C7

\footnotetext{
Montandon, F. Geogra. Helvetica (Bern) 111(2) $157-178$ (1948)

2. Derr, J.S. \& Persinger, M.A. J. sci. Explor. (in the press)

3. Duberger, R. et al. Tectonophysics (in the press).

4. Yamada, I., Masuda, K. \& Mizutani, H. Phys. Earth planet Int. 57, 157-168 (1989).

5. Mizutani, H., Ishido, T., Yokokura, T. \& Ohniski, S Geophys. res. Lett. 3, 365-368 (1976).

6. Zlotnicki, J. \& Le Mouël, J.L. Nature 343, 633-635 (1990).
}

NATURE · VOL $348 \cdot 6$ DECEMBER 1990 